\title{
A TAREFA DOS INTELECTUAIS DIANTE DA REALIDADE SOCIAL: DENÚNCIA OU COMBATE?
}

\author{
Mario Borges Netto ${ }^{1}$ \\ Maria Cristina Gomes Machado ${ }^{2}$
}

\begin{abstract}
RESUMO
O presente texto tem como proposta responder ao seguinte questionamento: qual a função do intelectual, denúncia ou combate? O que nos diz Florestan Fernandes sobre o papel do intelectual? Para correspondermos ao objetivo do texto, debatemos sobre as tarefas dos intelectuais no processo de transformação e democratização da sociedade brasileira, a partir dos escritos de Florestan Fernandes. Foi possível perceber que Florestan Fernandes segue uma tradição teórico-política de esquerda que defende a unidade entre ciência (teoria) e política (prática). Disso compreende-se que Florestan Fernandes considera que tanto a denúncia quanto o combate são tarefas complementares inerentes à conduta do intelectual, porém, fica evidente o peso atribuído por ele à iniciativa prática da luta política, ao combate. Para melhor apresentarmos a nossa análise e os resultados construídos pelo nosso estudo, organizamos o texto da seguinte forma: 1) apresentamos o debate sobre os intelectuais nos escritos de Karl Marx e Antonio Gramsci; 2) analisamos o papel do intelectual no processo de transformação social nos escritos de Florestan Fernandes; por fim, tecemos nossas conclusões.
\end{abstract}

Palavras-chave: História da educação; intelectuais; Florestan Fernandes.

\section{THE TASK OF INTELLECTUALS BEFORE THE SOCIAL REALITY: A COMPLAINT OR A COMBAT?}

\begin{abstract}
This paper has the purpose to answer the following question, which is the role of the intellectual, to denounce or to combat? What does Florestan Fernandes tell us about the role of intellectuals? To correspond to the purpose of the paper, we discuss about the tasks of intellectuals in the process of transformation and democratization of the Brazilian society, from the writings of Florestan Fernandes. It could be observed that Florestan Fernandes follows a theoretical and political tradition of the left-wing that embraces unity between science (theory) and politics (practice). It is understood that Florestan Fernandes believes that both the complaint and the combat are complementary tasks inherent to the conduct of the intellectual, however, it is clear the weight given by him to the practice initiative of the political struggle to the combat. To better present our analysis and results built by our study, we organized the text as follows: 1) we present the debate on intellectuals in the writings of Karl Marx and Antonio Gramsci; 2) we analyze the role of the intellectual in the process of social transformation in the writings of Florestan Fernandes; finally, we weave our conclusions.
\end{abstract}

Key words: History of education; intellectuals; Florestan Fernandes. 


\section{PARA INÍCIO DE CONVERSA ...}

Qual é o principal problema com que se defronta o intelectual na sociedade brasileira de hoje? Devemos ir à luta com a intenção elementar de revanche ou temos de retomar os fios da história e combater a reação diretamente no terreno que permitirá destruir o regime ditatorial de vez e para sempre? Em suma, denúncia ou combate? (FERNANDES, 2011, p.81).

Para que serve uma epígrafe? Em geral, é uma inscrição que antecipa o conteúdo de um texto ou apresenta de forma solene uma inspiração ou uma ideologia do autor. A epígrafe posta acima cumpre o primeiro fim, ou seja, ela anuncia o conteúdo do texto que se desenrolará nas próximas páginas. Porém, neste texto ela cumpre uma função a mais, qual seja, provocar. Em 1979, Florestan Fernandes abria sua fala na $31^{a}$ reunião anual da Sociedade Brasileira para o Progresso da Ciência (SBPC), com os questionamentos citados na epígrafe. Diferente das nossas finalidades para esse texto, Florestan Fernandes se propunha respondêlos, trazendo a baila reflexões cujas finalidades seriam fundamentar um programa de ação. Para nós, esses questionamentos não foram respondidos pela história, ainda são candentes e expressam um questionamento maior, a saber, "qual é o papel do intelectual no processo de transformação social?" Para não tratarmos diretamente da vivacidade e da atualidade desse questionamento e incomodar os intelectuais de espíritos delicados, iremos neste texto remeter esses questionamentos ao contexto histórico em que foram produzidos, colocando em destaque o debate de Florestan Fernandes sobre a tarefa do intelectual frente à realidade social. No entanto, alertamos que qualquer semelhança com os nossos dias não se trata de mera coincidência.

Florestan Fernandes é bem conhecido pela historiografia brasileira. Muito se tem falado e produzido sobre ele e sua obra. São comuns afirmações que o apresentam, com toda justiça, como um grande intelectual, como um dos poucos intelectuais brasileiros que teve sua obra discutida de forma tão aprofundada. (CUNHA, 2008). O destaque dado pela historiografia a Florestan Fernandes tem centralidade na sua inserção na luta política cotidiana em defesa dos direitos inalienáveis do ser humano, dentre eles a educação, e da democratização da sociedade brasileira. $O$ referido intelectual lutou ativamente contra o governo militar instaurado no Brasil (1964-1985), do qual foi vítima, quando em 1969 sofreu com a aposentadoria compulsória e foi exilado.

Atento às questões sociais de seu tempo, Florestan Fernandes se tornou um militante ativo, empunhou as bandeiras das classes subalternas, dentre elas, a da educação pública. Saviani (1996) e Buffa (1979) argumentam que a partir da década de 1950, Florestan Fernandes assumiu a postura de militante e divulgador da bandeira em prol da escola pública no Brasil. Em 1960, foi um dos líderes da Campanha em defesa da escola pública, que teve seu início em 04/05/1960, com a I Convenção Estadual em defesa da Escola Pública, em Ribeirão Preto, São Paulo, que posteriormente se irradiou para todo o Brasil. (BUFFA, 1979). Nessa Convenção Florestan Fernandes se destacou pelo empenho a favor da causa ali defendida; apresentou no plenário um texto em defesa da escola pública, elaborado por ele e por Fernando Henrique Cardoso, adjetivada como uma proposta de tendência socialista (BUFFA, 1979; SAVIANI, 1996), e foi o relator do substitutivo aprovado pela Convenção, que seria encaminhado ao Senado. Depois da realização da I Convenção, os trabalhos dos integrantes da Campanha em defesa da escola pública continuaram através de estudos, realizações de conferências e debates, em diversos estados, culminando na II Convenção em defesa da escola pública, da qual Florestan Fernandes participou ao lado de Octávio Ianni. Para Buffa (1979, p.63), Florestan Fernandes foi “[...] o batalhador incansável na luta pela escola pública, proferindo inúmeras conferências e publicando vários estudos". 
Florestan Fernandes não nutria a ilusão de que a universidade, e a educação de modo geral, seria mola mestra da transformação e democratização da sociedade, pois na história ela se apresentava como uma instituição conservadora; "a revolução não se faz na universidade" (FERNANDES, 2011, p.353), dizia. No entanto, a considerava um elemento importante para tal processo. Enxergava a universidade como uma instituição produtora de conhecimento que contribuía para a formação de novos intelectuais e que, a serviço da transformação social, se tornaria viva e atuante. Seus estudos sobre o ensino superior brasileiro revelavam que as "universidades" do Brasil se constituíam em redutos de intelectuais vestidos do "manto institucional" que se colocavam acima dos problemas sociais, observando-os do alto de suas "torres de marfim". Quando muito, denunciavam as mazelas pelas quais a sociedade brasileira passava. (FERNANDES, 1979; 2011). Lidar com a questão do intelectual a partir da obra de Florestan Fernandes nos condiciona a passar pelo debate sobre a função social do professor universitário, dentro e fora da universidade.

Eis o ponto de partida da nossa discussão: a função do intelectual, denúncia ou combate? O que nos diz Florestan Fernandes sobre o papel do intelectual? Para respondermos esses questionamentos propomos debater sobre as tarefas dos intelectuais no processo de transformação e democratização da sociedade brasileira a partir dos escritos de Florestan Fernandes. Para tanto, organizamos nossa exposição da seguinte forma: 1) apresentação do debate sobre os intelectuais nos escritos de Karl Marx e Antonio Gramsci, os quais contribuíram para a construção da tradição teórica de esquerda assumida por Florestan Fernandes; 2) análise do papel do intelectual no processo de transformação social nos escritos de Florestan Fernandes; por fim, teceremos nossas conclusões.

\section{A QUESTÃO DO INTELECTUAL NA OBRA DE KARL MARX E NOS ESCRITOS DE ANTONIO GRAMSCI}

O debate sobre os intelectuais, sua natureza de classe e função social é extenso e polissêmico. Diferentes estudiosos se debruçaram, e ainda se debruçam, sobre a temática, cada qual fundamentado nas mais diversas concepções teórico-metodológicas e autores, dentre os quais podemos citar: Weber, Sartre, Nizan, Benda e Ortega, Marx, Lênin, Gramsci. Privilegiaremos aqui os escritos de Karl Marx e Antonio Gramsci sobre o papel dos intelectuais, por entender que se constituem fundamentos para melhor compreendermos as teses de Florestan Fernandes sobre a função social do intelectual na sociedade capitalista.

O sentido do termo "intelectual" está na especificidade da espécie humana, que não tendo a sua existência garantida pela natureza, deve agir sobre ela e transformá-la através do trabalho. (SAVIANI, 2013). A atividade humana é caracterizada pela unidade trabalho intelectual e trabalho manual, uma atividade que articula mente e corpo, ação prática e teoria, trata-se de um ato manual com expressão teórica. Isso é o que levou Gramsci a afirmar que "todos os homens são intelectuais". (GRAMSCI, 2007, p.1516, tradução nossa). "Isso significa que se se pode falar de intelectuais, não se pode falar de não-intelectuais, porque nãointelectuais não existem". (GRAMSCI, 2007, p.1550, tradução nossa). Essa unidade permitiu Gramsci considerar que não existe um trabalho puramente manual, nem mesmo um trabalho puramente intelectual, "não existe atividade humana da qual se possa excluir toda intervenção intelectual, não se pode separar o homo faber do homo sapiens". (GRAMSCI, 2007, p.1550, tradução nossa).

O debate sobre a função social do intelectual encontrada nas obras de Marx e Gramsci ancora-se na base material da sociedade capitalista, na qual o trabalho é dividido entre as duas classes sociais fundamentais. O capitalismo possui como um dos seus fundamentos a propriedade privada, a partir dela a sociedade se divide em classes sociais: de um lado os que detêm dos meios de produção, de outro os que não os detêm. Com o advento da sociedade de 
classes, manifesta-se a divisão entre trabalho manual e intelectual, o que levou Gramsci a afirmar que apesar de todos os homens serem intelectuais, "[...] nem todos os homens desempenham na sociedade a função de intelectuais". (GRAMSCI, 2007, p.1516, tradução nossa). A história confirma essa assertiva gramsciana, nos revelando que desde as sociedades antigas, passando pelo medievo, o trabalho intelectual foi prerrogativa das classes detentoras dos meios de produção, das classes dominantes, relegando o trabalho manual às classes subalternas. De acordo com Saviani (2013), o aprofundamento dessa divisão em classes se intensificou com a divisão social do trabalho na sociedade capitalista, processo que ampliou a categoria dos intelectuais, tanto na quantidade quanto variação de modalidades que passam a fazer parte da intelectualidade. Além dos herdeiros das artes liberais medievais, quais sejam, os artistas, literatos, filósofos, teólogos, médicos e juristas, passaram a compor o campo intelectual novos sujeitos sociais, os cientistas, os técnicos industriais, engenheiros, agrônomos, jornalistas, administradores, gerentes de empresas, os agentes públicos, professores, dentre outros.

Marx e Gramsci em seus escritos denunciam essa divisão laboral e política entre produtores e planejadores, dirigidos e dirigentes, que diante das circunstâncias vivenciadas teorizam possibilidades e preconizam planos de ação para superar essa condição social. Em toda a sua obra, Marx não possui uma teoria sobre os intelectuais, mas nos debates teóricos e políticos com os hegelianos de esquerda dedica atenção especial à função social do filósofo. Nos seus escritos da década de $1840^{3}$ apresenta uma categoria que se tornaria um dos principais pilares da sua teoria, qual seja, a práxis. A práxis é a unidade da relação teoria e prática, a unidade da necessidade histórica e objetiva e da ação real e consciente dos homens, portanto, o fundamento da ação humana. Com base nessa premissa, Marx não dissocia ciência (teoria) e ação política (prática). Para o referido autor, é função do filósofo se inserir nos embates políticos e transformar a realidade, pois a sabedoria, qualidade eminente do filósofo, não deve se reduzir a mera contemplação, ela é também a capacidade racional de agir ou tomar decisões sobre casos particulares e concretos. O posicionamento marxiano sobre a função do filósofo, ou intelectual, ficou conhecida pela tese XI sobre Feuerbach, "os filósofos apenas interpretaram o mundo de diferentes maneiras; o que importa é transformá-lo". (MARX; ENGELS, 2007, p.535). Marx considera a prática política como elemento de intervenção na realidade material-objetiva e na vida social.

Diante disso, Marx considerou que o projeto revolucionário necessitaria de uma parcela da classe proletária fosse instruída, para levar adiante as reivindicações do proletariado e colocar em marcha as suas lutas. Essa parcela instruída foi denominada por Lênin e Gramsci de "vanguarda" e "intelectuais de novo tipo", respectivamente. A formação de uma base instruída torna-se fundamental no sistema teórico dos marxistas, pois considera a luta política um meio privilegiado, senão o único, para viabilizar a revolução. Os autores marxistas em geral acreditam que os trabalhadores deveriam disputar os espaços em todas as esferas sociais, desde o âmbito produtivo até a esfera político-jurídica, terreno de atuação dos intelectuais, e, portanto, reivindicar os direitos sociais e políticos ainda no sistema capitalista, vislumbrando a revolução e uma sociedade emancipada.

Nos escritos de Gramsci (2007), fica evidente que os intelectuais na organização da sociedade capitalista do século XX assumem papeis de mediadores entre o mundo da produção e o complexo superestrutural; eles se configuram como os profissionais especializados do grupo hegemônico que desempenham a atividade de garantir consentimento ativo das massas à direção dominante. De acordo com Gramsci (2007), os intelectuais não constituem uma classe autônoma, mas são sujeitos vinculados a uma das duas classes sociais fundamentais, os detentores dos meios de produção ou o proletariado. O que Gramsci nos alerta é que a origem de classe não garante o exercício e a luta política a favor da mesma. $\mathrm{Na}$ sociedade capitalista ocorrem dois tipos de formação dos intelectuais, ou eles são formados no 
interior da própria classe burguesa ou essa mesma classe pode escolher, dentre eles mesmos ou dentre os integrantes de outros grupos sociais, em quem confiar a atividade de direção e organização da cultura. Nas palavras de Gramsci,

Se não todos os empreendedores, ao menos uma elite deles deve ter uma capacidade de organizador da sociedade em geral, em todo o seu complexo organismo de serviços, até ao organismo estatal, pela necessidade de criar as condições mais favoráveis à expansão da própria classe; ou deve possuir pelo menos a capacidade de escolher os "commessi" (empregados especializados) nos quais confiar esta atividade organizadora das relações gerais externas aos negócios. Pode-se observar que os intelectuais "orgânicos" que cada nova classe cria com si mesma e elabora no seu desenvolvimento progressivo, são "especializações" de aspectos parciais da atividade primitiva do tipo social novo que a nova classe pôs a luz. (GRAMSCI, 2007, p.1513-1514, tradução nossa).

A categoria gramsciana "intelectuais orgânicos" explicita exatamente isso, um grupo de intelectuais nascidos na classe subalterna poderá ser formado para exercer a função de organizadores da cultura no interior de sua classe social originária a serviço do grupo hegemônico, contribuindo para a manutenção do sistema capitalista. Os intelectuais orgânicos são os profissionais especializados a serviço da hegemonia burguesa que exercem a função social de organização do consenso, são, portanto, organizadores da cultura e das relações jurídicas e político-estatais.

Gramsci salienta que na correlação de forças expressa na sociedade capitalista os dominados dão um consentimento ativo à dominação, que é construído e alimentado pelas classes hegemônicas por meio dos "aparelhos privados de hegemonia" e pelas ações dos intelectuais. Por meio dos "aparelhos oficiais", os intelectuais transmitem um ponto de vista classista como se fosse "universal", de todos, e a classe trabalhadora adere a essa visão de mundo que não lhe é própria e passa a agir de acordo com ela. Mas, o ponto que deve se destacar é que a adesão é consentida, ativa, ou seja, os próprios trabalhadores, ao vislumbrar no projeto societário capitalista elementos que lhes permitiriam uma condição melhor de vida, assumem esse projeto societário como seu e contribuem para que ele se efetive, como confirma o excerto a seguir:

A relação entre os intelectuais e o mundo da produção não é imediato, como acontece para os grupos sociais fundamentais, mas é "mediato", em diverso grau, por todo o tecido social, pelo complexo das estruturas, do qual exatamente os intelectuais são os "funcionários". [...] Estas funções são precisamente organizativas e conectivas. Os intelectuais são os funcionários especializados [commessi] do grupo dominante para o exercício das funções subalternas da hegemonia social e do governo político, isto é: 1) do consenso "espontâneo" dado pelas grandes massas da população ao encaminhamento empreendido à vida social pelo grupo fundamental dominante, consenso que nasce "historicamente" pelo prestígio (e consequentemente, pela confiança) decorrente do grupo dominante pela sua posição e pela sua função no mundo da produção; 2) do aparato de coerção estatal que assegura "legalmente" a disciplina daqueles grupos que não "consentem" nem ativamente nem passivamente, mas é constituído por toda a sociedade em prevenção dos momentos de crises no comando e na direção no qual o consenso espontâneo é menor (GRAMSCI, 2007, p.1518-1519, tradução nossa).

Gramsci (2007), em seus escritos, se preocupou com o que ele denominou de "aparelhos privados de hegemonia", pois são esses aparelhos que dão a formatação cultural ideológica a todos os homens, de modo que esses homens deem seus consentimentos ativos às 
mudanças do capitalismo, cujo fim é a sua manutenção. $\mathrm{O}$ autor desvela que o Estado, o Capital, seus aparelhos de hegemonia, não são entidades divinas com vontades próprias que fazem da classe trabalhadora os seus fantoches. O elemento que ele ressalta é: há sim uma dominação de uma classe sobre a outra, porém, isso não se concretiza somente pelas posições assumidas por ambas as classes fundamentais na esfera produtiva. Além disso, Gramsci (2007) refuta qualquer tipo de maniqueísmo que tente expressar teoricamente a dominação real, portanto, desconsidera as concepções vulgares do conceito de ideologia que por vezes é tratado como um espectro enganador que enfeitiça e conduz a classe trabalhadora à exploração. No entanto, Gramsci não desconsidera o aspecto ideológico das relações de classe, mas faz ressalvas sobre ele, pois compreende que as relações entre a estrutura e a superestrutura não são mecânicas e que a verdade não pode ser considerada como o único e principal elemento de libertação da classe trabalhadora do jugo do capital. O que está em jogo aqui é o questionamento inicial do nosso texto, denúncia ou combate? O que nos fica claro é o lado da trincheira em que se encontram Marx e Gramsci. Assim como Marx, o autor italiano defende que a denúncia, ou seja, o desvelar da verdade, faz parte da construção do processo revolucionário, pois revela as bases reais das relações de classe na sociedade capitalista, porém, o determinante é o combate, ou seja, a ação prática e política da classe trabalhadora. Nos dizeres de Marx (2010, p.151) "A arma da crítica não pode, é claro, substituir a crítica da arma, o poder material tem de ser derrubado pelo poder material, mas a teoria também se torna força material quando se apodera das massas [...] tão logo se torna radical”.

Mesmo com um retrospecto pessimista, Gramsci (2007) considera que os intelectuais têm papel fundamental para a construção de um movimento revolucionário, vislumbrando assim a necessidade da formação de um novo tipo de intelectual. Assim como Marx, Gramsci não vê que a transformação radical da sociedade seja algo simples. Considera que não são as crises vivenciadas pelo capital e a miséria daí decorrente que conduzirão o sistema capitalista ao colapso, pois se assim fosse, o capitalismo havia se extinguido na primeira grande crise estrutural de 1873. O autor italiano nutre um grande pessimismo em relação à visão espontaneísta dos grupos de esquerda sobre a revolução. Gramsci (2007) concebe que o capitalismo é um sistema em que as crises constituem a sua natureza, mas o próprio sistema produz as soluções para os seus problemas sociais. Em outras palavras, o capitalismo cria suas próprias mazelas e ao mesmo tempo, produz o antídoto que as combaterá. Disso entende-se que as convulsões sociais sofridas pelo sistema capitalista não são capazes de destruí-lo, pois somente os homens, ou seja, os seus criadores, aqueles que o mantêm, podem revolucionar a sociedade e desencadear o fim do sistema econômico vigente. Gramsci em seus escritos atribui muita responsabilidade à ação política do sujeito, pois é o homem quem constrói e muda a história, portanto, só ele pode fazer a revolução. É atribuído, portanto, grande peso ao homem no que se refere à possibilidade de levar a cabo o processo revolucionário no interior das sociedades capitalistas avançadas, intensificando a necessidade da criação de intelectuais orgânicos de um novo tipo.

As inferências gramsciana sobre a formação de um novo tipo de intelectual orgânico remetem à ideia de formar intelectuais que emirjam do interior da classe trabalhadora e se coloquem a serviço dela mesma, na constituição de uma visão de mundo que lhe seja própria e que contribua para a revolução. $O$ ponto de partida para a criação desse novo tipo de intelectual é a elaboração crítica da atividade intelectual que já existe em cada um dos membros da classe subalterna, desenvolvendo-a em outra direção. Saviani (2013, p.226) nos mostra que essa tarefa implica dois momentos simultâneos e articulados entre si:

[...] um momento negativo que consiste na crítica da concepção dominante (a ideologia burguesa); e um momento positivo que significa trabalhar o senso comum buscando extrair o seu núcleo válido (o bom senso) para lhe dar 
expressão elaborada com vistas à formação de uma concepção de mundo adequada aos interesses populares.

A finalidade desse processo é inverter o processo prático corrente fundado na concepção dominante, por meio da qual a relação entre intelectuais e massa é estimulada a manter e se possível ampliar a distância que os separam. Gramsci (2007) postula que a filosofia da práxis deve propiciar o estreitamento da relação entre intelectuais e massa, tendo como finalidade a elevação dos indivíduos que se encontram na base da classe proletária à condição de intelectuais. "No mundo moderno a educação técnica, estritamente ligada ao trabalho industrial também ao mais primitivo ou desqualificado, deve formar a base do novo tipo de intelectual”. (GRAMSCI, 2007, p.1551, tradução nossa).

Em concordância, Saviani (2013) considera que o processo de formação do novo intelectual deverá levar em consideração a nova forma de sociedade centrada na cidade e na indústria. Nas palavras de Gramsci (2007, p. 1551, tradução nossa) isso significa que "o modo de ser do novo intelectual não pode mais consistir na eloqüência [...]". Em lugar disso, deve, "[...] misturar-se ativamente à vida prática, como construtor, organizador, 'persuasor permanentemente' $[\ldots]$ "., porque não devem mais se constituir num puro orador, como os tipos tradicionais e vulgares de intelectuais, mas, ao contrário, deverá se elevar "[...] da técnicatrabalho [...] à técnica-ciência e à concepção humanística histórica, sem a qual se permanece 'especialista' e não se torna 'dirigente' (especialista + político)". Consideremos a seguir o posicionamento de Florestan Fernandes ante a mesma questão.

\section{FLORESTAN FERNANDES E OS UNIVERSITÁRIOS: O COMBATE COMO EXPRESSÃO DA AÇÃO POLÍTICA DO INTELECTUAL}

Como visto anteriormente, tanto para Marx quanto para Gramsci, a função social dos intelectuais é bem delimitada pelo aspecto combativo-atuante na realidade social em que está inserido. Assim como os autores anteriormente citados, Florestan Fernandes não se furtou a esse debate, ao contrário disso, se inseriu nele e defendeu a tese de que o cientista social, enquanto intelectual, deve adentrar aos debates candentes de sua realidade e à luta política diária. Florestan Fernandes segue essa tradição teórica de esquerda, fundamentada em Marx, que concebe de modo unitário a relação ciência e política, e considera a necessidade do intelectual de exercer a ação de militante.

A questão do intelectual se revela em vários escritos que se encontram dispersos por toda a obra de Florestan Fernandes. Por considerar a ciência como um elemento de interpretação e transformação social, se debruça sobre as responsabilidades e a função social do intelectual diante dos problemas vivenciados pela sociedade brasileira. Em todos os escritos o denominador comum é a defesa intransigente do aspecto combativo que o intelectual deve assumir diante da realidade, ora no interior do ofício de sociólogo, ora no âmbito político-social.

No que se refere ao debate sobre os intelectuais no interior das discussões sobre a sociologia e sobre o sociólogo, o que torna a leitura dos escritos de Florestan Fernandes necessária para os nossos dias é que elas não tratam dos intelectuais de modo geral, ou seja, não discute quem é o intelectual, mas debate os aspectos éticos da conduta do intelectual. Isto leva Fernandes a problematizar as ações dos seus próprios pares, os sociólogos brasileiros e os professores universitários. Em seus escritos sobre a constituição da sociologia brasileira, o autor critica o posicionamento dos sociólogos brasileiros que se preocupavam mais com a produção do conhecimento científico que com o uso social dos mesmos. O referido intelectual uspiano advertia já na década de 1960 que os sociólogos brasileiros se distanciavam a passos largos das condutas morais dos pioneiros da sociologia, os quais haviam aderido a uma ética de responsabilidade científica, que era solapada pelos aprendizes tupiniquins. As novas 
gerações de sociólogos brasileiros se blindavam com o escudo do discurso da neutralidade científica, defendendo-se das responsabilidades que suas produções científicas os impunham.

Todavia, por paradoxal que pareça, os pioneiros da sociologia aderiram a uma ética de responsabilidade científica bem antes dos físicos, dos químicos, dos biólogos de nossos dias. Os seus continuadores não lhes seguiram as pegadas, alegando que suas preocupações envolviam atitudes e opções extracientíficas (ou melhor: atinentes à filosofia social). Com isso, em vez de conformar as preocupações pragmáticas iniciais ao horizonte intelectual dos cientistas, descartaram-se delas, em troca da assimilação de padrões de trabalho então vigentes no campo da física, da química ou da biologia. Em outras palavras, optaram pelo isolamento e pela abstenção diante dos dilemas morais criados pela civilização baseada na ciência e na tecnologia científica. (FERNANDES, 1963, p.132).

Seguindo essa linha de raciocínio, Florestan Fernandes defende que o cientista social deveria romper com a segregação cultural imposta pelos círculos de cientistas e pelas elites conservadoras em relação à coletividade, e assumir sua responsabilidade e o papel de mediador entre os problemas sociais e a população, pois considerava a Ciências Sociais como a teoria explicativa e fundamento da transformação da sociedade. $\mathrm{O}$ autor em destaque compreende que era característica do contexto "[...] a exclusão sistemática dos cientistas dos papéis sociais ativos, através dos quais os dados e as descobertas da ciência [foram aplicados por outrem] à solução dos problemas materiais, morais e educacionais do homem". (FERNANDES, 1963, p.129). Para Fernandes (1968, p.200) os cientistas sociais eram encarados pela sociedade brasileira como "subversivos" e, com frequência, eram repudiados como agentes de "influências perturbadoras". No entanto, considerava também que essa situação era, em certa medida, sustentada pela postura negligente do próprio cientista, seja pela falta de interesse em se envolver com as questões sociais e morais dos problemas da nação, seja pelas frustrações que as circunstâncias os impunham. Mas, ressalta que esse distanciamento dos problemas sociais "[...] põe o destino da civilização baseada na ciência e na tecnologia científica em mãos pouco ou mal qualificadas". (FERNANDES, 1963, p.129).

Diante desse cenário, Florestan Fernandes defendia que o sociólogo deveria se assumir como um intelectual participante. Essa postura corresponde à inserção do intelectual nos embates sociais e políticos e a função de comunicar, no sentido de traduzir, à população as causas e consequências dos chamados "magnos problemas nacionais". (FERNANDES, 1963). O próprio autor é exemplo desse tipo de intelectual por ele preconizado; ao longo de sua carreira acadêmica e política exerceu as duas funções anteriormente citadas: se inseriu na luta política pela escola pública, pela reforma universitária e pela redemocratização da sociedade brasileira, dentre outras, e ao mesmo tempo, se tornou um grande publicista, denunciando e enunciando em jornais e revistas seus posicionamentos diante dos problemas sociais.

Para melhor exemplificar o que acabamos de afirmar escolhemos as ações de Florestan Fernandes na Campanha em defesa da escola pública como expressão prática das atuações que o sociólogo deve assumir diante das questões sociais. Conforme Fernandes relata, a sua produção intelectual, inserção no debate e a atuação enquanto intelectual correspondeu, simultaneamente, a dois objetivos:

Um de informação e propaganda: ele impunha que se desse atenção sistemática à enumeração e à divulgação das lacunas, inconsistências e omissões do projeto de lei sôbre Diretrizes e Bases da Educação Nacional. Outro, de caráter formativo e doutrinário; êle determinava a formalização e a disseminação em linguagem vulgar de idéias concernentes ao estado do ensino no Brasil, à natureza da filosofia democrática da educação e aos requisitos educacionais de uma ordem econômica, social e política competitiva. (FERNANDES, 1963, p.117-118). 
Percebe-se que a participação de Florestan Fernandes na luta em defesa da escola pública assumia uma função de reeducação da população brasileira, colocando-a em contato com os problemas educacionais brasileiros e desvelando as lacunas, omissões e os problemas inerentes ao projeto de lei referente à LDB, que seria promulgada em 1961. Em relação à ação de Florestan Fernandes é possível considerar que ele não visava a adesão das massas ao seu posicionamento, mas a alteração de um modo de ser e pensar os aspectos vitais da vida social organizada. Seus esforços intelectuais buscavam fazer com que os leigos entendessem e aceitassem os conhecimentos e convicções resultantes da análise sociológica dos problemas educacionais brasileiros. Para Florestan Fernandes é da natureza dos intelectuais serem fatores humanos de dinamização do processo de mudanças sociais, especialmente como técnicoespecialistas, mas também o exercício do papel de ideólogos. (FERNANDES, 1968).

Outro aspecto que sobressai nos escritos de Florestan Fernandes, complementar ao exposto anteriormente, é o seu ataque desferido ao governo militar brasileiro e a convocação enunciada aos intelectuais para a luta em prol da revolução democrática. Mesmo em um contexto de liberdade restrita, expressão política de um governo autoritário, Florestan Fernandes (1968, p.187) proclama a participação ativa dos intelectuais brasileiros no embate político externo as universidades.

[...] os homens devem estar permanentemente preparados para vigiar seus deveres inalienáveis e usufruir seus direitos legítimos. Devem, pois, arcar com uma luta permanente, consigo mesmos e com os outros, na defesa de prerrogativas em que se fundam a dignidade humana e o próprio sentido da vida civilizada.

Para tanto, exige dos seus pares o posicionamento em relação à revolução democrática, pois Florestan Fernandes (2011) considera que o primeiro passo a ser tomado pelos intelectuais na luta pela democratização da sociedade seria a definição da relação de cada um com a revolução democrática e a assunção das responsabilidades consequentes da tomada de posição, ideia sintetizada na passagem abaixo:

Neste momento, as tarefas se redefinem em duas direções: os intelectuais estão livres para se comporem como servos do poder ou para se afirmarem como paladinos da revolução democrática. Os que preferirem as "malhas do governo" poderão assumir, agora com toda a clareza e responsabilidade, os papéis políticos de intelectuais orgânicos da sociedade burguesa. Os que preferirem a liberação do homem e a liberação nacional poderão travar o combate que associa o fim da ditadura com a construção de uma nova sociedade no Brasil. No mínimo, terão de arcar, agora com toda a clareza e responsabilidade, com os papéis políticos de uma revolução democrática impulsionada pela maioria e conduzida pelos estratos mais organizados da classe trabalhadora. (FERNANDES, 2011, p.88).

Nota-se que novamente Florestan Fernandes orienta os intelectuais brasileiros a se preocuparem menos com os problemas internos das instituições, libertando a reflexão crítica e a atividade criadora, que se torna peso morto quando focada somente na "racionalização da produção científica" e no "uso das descobertas da ciência". (FERNANDES, 2011, p.89). Essa ênfase nos aspectos internos da universidade cria uma paralisia do pensamento crítico e militante em um nível pré-político. Florestan Fernandes postula que os intelectuais brasileiros devem focalizar seus esforços para além dos muros da universidade, devem contribuir com a luta pela consolidação da democracia de modo a colaborar com os movimentos da classe trabalhadora no processo revolucionário. 
E, indo mais longe, acredito que o dever maior do intelectual, em sua tentativa de ajustar-se criadoramente à sociedade brasileira, objetiva-se na obrigação permanente de contribuir, como puder, para estender e aprofundar o apêgo do homem médio ao estilo democrático de vida. Isso significa, em outras palavras, que os intelectuais brasileiros devem ser paladinos convictos e intransigentes da causa da democracia. (FERNANDES, 1968, p.194-195).

Para Florestan Fernandes (2011, p.89), "as classes trabalhadoras precisam [...] da colaboração orgânica dos intelectuais", por isso, a intelectualidade brasileira deveria pensar em "[...] como sanar as carências institucionais que pesam sobre o movimento sindical e operário, como fortalecer politicamente esse movimento, como imprimir ao impacto político das classes trabalhadoras sobre a revolução democrática o impulso mais durador e liberador possível etc". (FERNANDES, 2011, p.89). Mesmo diante da necessidade social e da vivacidade de suas convicções, Fernandes (1968) revela que a tarefa do intelectual é árdua e requer consciência história, coragem cívica e disposição política. O referido autor considera que a existência de alternativas pode contribuir para o imobilismo político e social do intelectual; dentre todas há a alternativa de negar as atividades extra-universitárias, o exercício político e a luta pela revolução democrática.

Essas formulações trazem consigo uma crítica à apatia política da intelectualidade brasileira. Na medida em que Fernandes (2011) convoca todos a assumirem um posicionamento frente à realidade política da nação, provoca-os cobrando compromisso intelectual com os problemas nacionais. A realidade brasileira regida pelo governo militar aponta para a necessidade da intensificação dos esforços na perspectiva da mudança, não para uma participação tangencial e descompromissada. A transformação social pautada no processo de redemocratização da sociedade brasileira requer do intelectual que "[...] ele se desvencilhe do orgulho profissional e do manto protetor das instituições especializadas; ela começa, portanto, como uma libertação da inteligência inventiva, que proletariza o intelectual, iguala-o às demais forças da revolução democrática”. (FERNANDES, 2011, p.90).

Disso percebemos que nos escritos de Florestan Fernandes (1963; 1968; 2011) reaparece a crença na luta política como instrumento privilegiado do processo revolucionário, tal como na obra de Marx e nos textos gramscianos. Para Fernandes a construção de uma sociedade pós-capitalismo não se prepara com medidas puramente econômicas e sim com a transformação política da sociedade, por isso a ênfase dada por ele ao aspecto político-moral da função social dos intelectuais. Em função disso, considera que os intelectuais brasileiros devem fazer da luta pela democracia e pelos direitos inalienáveis dos homens os seus grandes objetivos históricos. "Para realizar êsse[s] objetivo[s], [diz Fernandes], não devemos temer incompreensões, represálias ou o perigo de sermos silenciados. Adotar outra orientação seria o mesmo que aceitar o silêncio e acumpliciar-se com a neutralização da inteligência". (FERNANDES, 1968, p.196).

É possível perceber que é patente na obra de Florestan Fernandes a sua empresa para que os intelectuais brasileiros extrapolem os muros das universidades e se envolvam com os problemas nacionais. Conclama a todos a contribuir para o processo de restauração e consolidação da democracia na sociedade brasileira. Isso não se caracteriza como uma apologia à negligência e à falta de compromisso com a atividade laboral direta dos intelectuais, seja dos professores universitários com o ensino e a pesquisa, seja dos profissionais liberais com as suas atividades; porém, cumpre a função de uma convocatória a todos os intelectuais que enquanto partícipes de um tipo de governo republicano, assumam suas responsabilidades de cidadãos e se preocupem com os problemas concretos da nação e contribuam com a sua solução. 


\section{CONSIDERAÇÕES FINAIS}

Só é fraco, cego e impotente o intelectual que não sabe discernir a natureza de sua missão na sociedade.

Florestan Fernandes (1968, p.202).

O texto exposto buscou debater e apresentar as funções sociais atribuídas por Florestan Fernandes aos intelectuais brasileiros, buscando respostas para os seguintes questionamentos, qual a função social do intelectual, denúncia ou combate? O que nos revela Florestan Fernandes sobre o papel do intelectual na sociedade brasileira? Foi possível perceber que nos escritos de Florestan Fernandes por nós trabalhados a resposta se faz clara. Seguindo uma tradição teórico-política de esquerda, Fernandes reafirma a tese de Marx e Gramsci da unidade entre ciência (teoria) e política (prática) e considera que tanto a denúncia quanto o combate são tarefas complementares e inerentes à conduta do intelectual. No entanto é evidente o peso que os três os autores (Marx; Gramsci e Fernandes) atribuem à iniciativa prática da luta política, ao combate.

Firme de suas convicções, Florestan Fernandes em seus escritos faz repetidos apelos aos intelectuais para se envolverem com as questões sociais candentes de seu país. Numa realidade como a brasileira, defendia Fernandes (1968, p.187), é necessário que todos os cidadãos, em especial os intelectuais, tenham a "[...] clara e firme noção daquilo por que lutam, como condição mesma de sua segurança e de sua confiança nos critérios de opção ou de atuação social escolhidos". O referido autor atribui a todos os cidadãos a responsabilidade com os rumos da sociedade, porém destaca que ao contrário dos outros agentes sociais, os intelectuais devem lidar "[...] de modo consciente e inteligente com os elementos de racionalidade que são acessíveis à sua atuação social”. (FERNANDES, 1968, p.193). Isso não quer dizer que Fernandes os considere melhores ou piores que os outros, muito menos que eles estejam livres dos influxos dos interesses e das ideologias, contudo, caberia primeiramente a eles a tarefa de "[...] compreender a natureza real das exigências do estilo democrático de vida. Êle também deve ser o primeiro a propagar essa verdade e o último a consentir em que ela seja traída ou pervertida". (FERNANDES, 1968, p.196). Em outras palavras, Fernandes cobra a responsabilidade ética e o compromisso social daqueles que têm como tarefa a produção de conhecimento. Além do que, mais que os seus próprios dilemas sociais e pessoais, o intelectual deve estar atento "[...] à contribuição positiva que a sociedade brasileira tem o direito de esperar de seus intelectuais conscientes, aptos para o desempenho da porção de papéis sociais que possuem um conteúdo ou uma significação históricos". (FERNANDES, 1968, p.187).

Dessa perspectiva, se a sua consciência não estiver adormecida, à posição do intelectual é inerente um drama moral considerável, pois, por vezes, se vê na obrigação de lutar por alvos que não correspondem totalmente às suas concepções de equidade social. $\mathrm{Na}$ proporção que enxerga mais longe, nem sempre o intelectual deseja as soluções viáveis com entusiasmo. Apesar disso, devido à tarefa inerente do cientista, qual seja, estabelecer a relação entre as soluções possíveis e as necessidades da realidade em que vive, sente-se compelido a defendê-las com zelo e tenacidade. (FERNANDES, 1968). Entendemos que a questão que está em jogo não é só em "ficar em paz com a consciência", mas o essencial é perceber e tentar por em prática aquilo que precisa ser feito para que os problemas da nação sejam solucionados. No que diz respeito às questões políticas de seu contexto, cabe aos intelectuais "[...] pôr em prática aquilo que precisa ser feito para que o estilo democrático de vida não se corrompa, transformando-se no seu oposto, a sujeição consentida de uma maioria fraca a uma minoria prepotente". (FERNANDES, 1968, p.187).

Do exposto podemos sintetizar que para Florestan Fernandes a construção de uma sociedade mais justa e igualitária não se efetiva somente com medidas puramente econômicas, 
mas atribui grande peso ao aspecto e à ação política, segundo dois princípios fundamentais de natureza complementar: de um lado, a constituição de uma sociedade em que os bens e serviços fundamentais ao atendimento das necessidades básicas da pessoa humana não sejam objeto de apropriação privada. De outro, a criação de um regime político em que os grandes objetivos da vida social, bem como o exercício dos poderes, de qualquer natureza, sejam efetivamente definidos diretamente pelo povo e submetidos ao seu controle, com respeito absoluto aos direitos inalienáveis dos homens.

\section{REFERÊNCIAS}

BUFFA, Ester. Ideologias em conflito: escola pública e escola privada. São Paulo: Cortez e Moraes, 1979.

CUNHA, Marcus Vinícius da. Florestan Fernandes, arquiteto da razão. In. FARIA FILHO, Luciano Mendes de (Org.). Pensadores sociais e história da educação. 2 ed. Belo Horizonte, MG: Autêntica Editora, 2008.

FERNANDES, Florestan. A sociologia numa era de revolução social. São Paulo, SP: Companhia Editora Nacional, 1963.

FERNANDES, Florestan. A universidade brasileira: reforma ou revolução? $2^{a}$ ed. São Paulo, SP: Alfa-Omega, 1979.

FERNANDES, Florestan. Brasil: em compasso de espera: pequenos escritos políticos. Rio de Janeiro, RJ: Editora UFRJ, 2011.

FERNANDES, Florestan. Sociedade de classes e subdesenvolvimento. Rio de Janeiro, RJ: Zahar, 1968.

GRAMSCI, Antonio. Quaderni del carcere - Edizione critica dell'Istituto Gramsci. A cura di Valentino Gerratana. Turim: Einaudi, 2007, 4 vol.

MARX, Karl. Crítica da filosofia do direito de Hegel. Tradução de Rubens Enderle e Leonardo de Deus. 2. ed. São Paulo, SP: Boitempo, 2010.

MARX, Karl; ENGELS, Friedrich. A ideologia Alemã: crítica da mais recente filosofia alemã em seus representantes Feuerbach, B. Bauer e Stirner, e do socialismo alemão em seus diferentes profetas (1845-1846). Tradução de Rubens Enderle, Nélio Schneider e Luciano Cavini Martorano. São Paulo: Boitempo, 2007.

SAVIANI, Dermeval. Aberturas para a história da educação: do debate teóricometodológico no campo da história ao debate sobre a construção do sistema nacional de educação no Brasil. Campinas, SP: Autores Associados, 2013.

SAVIANI, Dermeval. Florestan Fernandes e a educação. Estudos Avançados, São Paulo, v.10, n.26, p.71-87, jan.-abr. 1996.

\footnotetext{
${ }^{1}$ Mestre em Educação pela Universidade Federal de Uberlândia. Professor do curso de graduação em Pedagogia da Universidade Federal do Tocantins, campus universitário de Tocantinópolis. Email: borgesnetto@uft.edu.br

${ }^{2}$ Doutora em Educação pela Universidade Estadual de Campinas. Professora do Programa de Pós-Graduação em Educação da Universidade Estadual de Maringá. Email: mcgmachado@uem.br

${ }^{3}$ Estamos fazendo remissão às seguintes obras: Crítica da filosofia do direito de Hegel; Manuscritos econômicofilosóficos; A ideologia Alemã; A sagrada família ou a crítica da Crítica crítica.
}

Recebido: maio/2015 Aprovado: jun/2015 